\title{
Desemprego e Juventude: Jovens em Busca do Primeiro Emprego
}

Unemployment and Youth: young in their search for the first job

Luciana Fim Wickert

Universidade Federal do Rio Grande do Su 


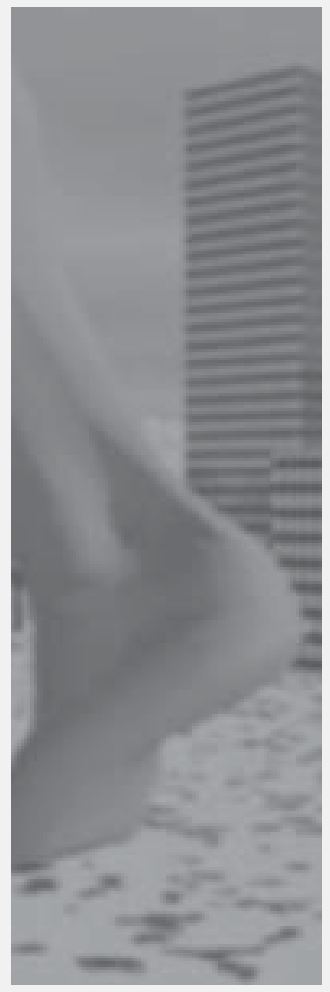

Resumo: O texto discute os impasses da inserção profissional e seus impactos nos modos de subjetivação de jovens de 16 a 24 anos que estão em busca de seu primeiro emprego. Os dados, obtidos através de entrevistas com inscritos no Programa Primeiro Emprego/RS, revelam que o desemprego afeta os processos de filiação social dos jovens e provoca uma produção de subjetividade marcada pelo sofrimento decorrente do aplacamento da vontade de potência.

Palavras-chave: juventude, trabalho, subjetivação, Programa Primeiro Emprego.

Abstract: This article discusses the professional insertion impasses and their impact on the mode of subjectivation of young aging from 16 to 24 years old in their search for the first job. The data, obtained through interviews whom registered in the Programa Primeiro Emprego/RS (First Job Program), indicate that unemployment affects the young social filliation process and provides the production of a kind of subjectivity marked by the suffering that results from the mitigation of the will to power.

Key words: youth, work, subjectivation, First Job Program.

\section{Jovens em Busca do Primeiro Emprego}

A proposta deste artigo é apresentar os dados da pesquisa de dissertação Desemprego e juventude: jovens em busca do primeiro emprego, desenvolvida no Programa de PósGraduação em Psicologia Social e Institucional, da UFRGS, no período de 2000 a 2002.

Este trabalho discute os modos de subjetivação de jovens de 16 a 24 anos que estão em busca de seu primeiro emprego. Sua relevância centrase no entendimento de que, apesar do aumento dos níveis de desemprego e da participação dos sujeitos com menos de 24 anos na categoria dos desempregados, os jovens continuam a ser preparados/objetivados para se tornarem trabalhadores assalariados.

Foram realizadas entrevistas abertas com inscritos no Programa Primeiro Emprego, programa de inserção de jovens no mercado de trabalho, do Governo do Estado do Rio Grande do Sul.

A partir de conceitos de Foucault, Nietzsche e Castel, enfoca-se a noção de desemprego como um processo de desfiliação, como algo que coloca os jovens à parte dos espaços de reconhecimento social, aponta-se para uma produção subjetiva marcada pelo sofrimento decorrente do aplacamento da vontade de potência.

\section{Cenário socio-histórico da pesquisa}

Nas últimas décadas, efetivaram-se transformações em escala mundial que redefiniram a dinâmica econômica, os modos de gestão empresarial, o mercado de trabalho, as condições de vida e de identidade do 
"A mercadoria força de trabalho tema particularidade de, legalmente, a partir do contrato, pertencer ao capitalista, mas continuar sob o controle físico do seu portador."

Colbari trabalhador. Esse processo tem indicado a constituição de um novo paradigma socioeconômico, que se distingue do tayloristafordista, vigente em boa parte do século XX (Cattani, 1999).

Tais mudanças afetam os modos de ser e de viver, pois, como assinala Colbari (1995), o taylorismo e o fordismo não se reduziram a simples conjuntos de princípios de caráter técnico e organizacional, mas exprimiram a racionalização explícita da produção capitalista, consolidando a subordinação real do trabalho ao capital. Essa subordinação se efetivou com a constituição de um regime de verdade valorativo do trabalho.

A problematização da valorização do trabalho é fundamental à nossa discussão por remeternos aos modos de subjetivação do período taylorista-fordista e da atualidade. Podemos conceituar modos de subjetivação como a forma pela qual os homens, ao relacionaremse com os regimes de verdade próprios de cada período histórico, se constituem sujeitos de suas próprias ações (Eizirik, 1997, Nardi, 2002). Conforme Ortega (1999), a construção de si, que se dá na subjetivação, nunca ocorre de modo isolado, pois inexistem auto-estilizações na solidão, ou seja, não há a possibilidade de constituição do que comumente se chama subjetividade sem a relação com o outro.

É no campo das relações com o outro que o sujeito de depara com os códigos e os regimes de verdade de sua época, ou seja, com as verdades construídas e legitimadas socialmente, verdades que sustentam e caracterizam o modo como os sujeitos se reconhecem e se governam (Nardi, 2002).

Entende-se que o paradigma taylorista-fordista contribuiu para o fortalecimento de uma ética valorativa do trabalho, que já vinha constituindose desde os meados do capitalismo. É importante destacarmos que a valorização do trabalho não foi algo espontâneo ou rápido. Para que o capitalismo se efetivasse como um modelo social e como uma forma de organização econômica, muitos foram os processos, os esquemas de controle e os dispositivos utilizados.

Em termos de acontecimentos, o que se teve, primeiramente, foi a utilização de esquemas coercitivos que objetivavam obrigar os pobres a trabalhar. Diante da ineficácia de tais esquemas, estes foram, paulatinamente, substituídos por dispositivos científicodisciplinares, ou seja, por mecanismos de saber e poder que constituíram, ao longo do tempo, uma valoração/dignificação do trabalho, estabelecendo relações entre trabalho, honestidade e dignidade. Então, o trabalho, que até o advento do capitalismo era considerado algo aviltante, passa a ser valorizado e considerado porta de acesso ao lugar social. Tal processo se fez necessário, pois, para que o engendramento capitalístico vigorasse; era preciso que suas premissas fossem assumidas pelos homens, afinal:

"A mercadoria força de trabalho tem a particularidade de, legalmente, a partir do contrato, pertencer ao capitalista, mas continuar sob o controle físico do seu portador. A adesão ao trabalho e o engajamento subjetivo do trabalhador no processo produtivo não estão plenamente assegurados pelo aspecto contratual da relação de compra e venda da força de trabalho; presumem sempre a (boa) vontade do trabalhador de desprender-se de suas capacidades física e intelectual e canalizá-las para a atividade produtiva" (Colbari, 1995, p. 12).

Diante dessa necessidade do capitalismo, a adesão ao trabalho e o engajamento subjetivo no processo produtivo passam a estar sob a responsabilidade de inúmeras instituições, que se organizam a fim de cumprir esse estatuto social. O termo instituição é utilizado na seguinte concepção: conjunto de normas e de valores instituído sob a forma de regimes de verdade, que estabelece e cristaliza provisoriamente as formas de relação social. 
O processo institucional não consegue abarcar o fluxo de forças que constituem o que se entende por poder. As instituições são práticas, são mecanismos operatórios, que tentam fixálo sob uma função homogenizadora e reprodutora, mas que não obtêm êxito total no seu intuito (Deleuze, 1988). Essa impossibilidade de total controle do poder se deve às suas características de produção, de positividade, pois, quando nos referimos ao poder, remetemo- nos à conceituação foucaultiana, que o entende como diagramático, isto é, como campo de forças dispersas que mobiliza matérias e funções não-estratificadas. Caracteriza-se por não ser essencialmente repressivo, visto que incita, induz, produz; não ser possuído, somente exercido, passando tanto pelos dominantes quanto pelos dominados, existindo na relação, mas não localizável. Como coloca Deleuze “...um exercício de poder aparece como um afeto, já que a própria força se define por seu poder de afetar outras forças" (1988, p. 79). Dessa forma, a relação de poder é ação sobre ações, é "condução de condutas" (Foucault, 1988).

O exercício de poder não é um dado institucional, tampouco uma estrutura que se mantém ou se rompe, pois não tem esse caráter localizável; está sempre em processo de transformação, de elaboração, de organização, provendo diferentes procedimentos de acordo com as circunstâncias que se apresentam (Foucault, 1988). São essas características de positividade de poder que possibilitam rupturas nos regimes de verdade. Como problematiza Nardi (2002), as verdades servem como justificativa para as formas de dominação e de resistência que marcam os modos de subjetivação de cada contexto histórico. Desse modo, "O regime de verdades próprio do capitalismo nos seus diferentes períodos permite explicar e justificar as posições de classe, o lugar dos sujeitos na estrutura social, as possibilidades e as restrições à mobilidade social" (Nardi, 2002, p.22).

É importante destacarmos a ação de algumas instituições no fortalecimento da ética valorativa e identificadora do trabalho, entre elas, a família e a escola. Como escreve Colbari, "a preparação para o trabalho e para o desenvolvimento de papéis sociais determinados é um componente do processo de sociabilização que ocorre no interior da família..." (1995, p. 114). Diante de um processo de sociabilização que prevê a filiação social ${ }^{1}$ atrelada ao processo de trabalho assalariado, cabe à família preparar os seus membros para essa inserção. Cumpre à família "...uma função estabilizadora, que complementa a função socializadora de adequar as personalidades ao desempenho de papéis padronizados culturalmente" (Cooper apud Colbari, 1995, p. 133; Rodrigues apud Colbari, 1995, p. 133). É imprescindível que tenhamos claro que não devemos considerar a família exclusivamente como mera reprodutora dos padrões sociais, pois também apresenta possibilidades de singularização e diferença. É ela que, perpassada por inúmeras instituições, tem-se encarregado de sustentar os processos de sociabilização, ficando sob sua responsabilidade desacelerar o avanço do individualismo, ao mesmo tempo em que o articula com as necessidades coletivas. Como coloca Ariès, "é como se a família moderna tivesse substituído as antigas relações sociais desaparecidas para permitir ao homem escapar a uma insustentável solidão moral" (1981, p. 274).

Cabe aqui destacarmos a função social das organizações escolares, visto que estas foram estruturadas para atender as necessidades de expansão do capitalismo, tendo como foco central a preparação dos futuros trabalhadores. Por essa razão, faz-se relevante discutirmos brevemente a instituição escolar, principalmente ao analisarmos que, "em situação ideal", crianças e adolescentes precisam de, no mínimo, onze anos para completar o nível médio de ensino.

Nesse aspecto, a contribuição de Foucault em "Vigiar e Punir" (1987) deve ser retomada, pois o autor enfatiza o processo de disciplinarização e hierarquização das escolas como um dos dispositivos de docilização dos corpos necessários ao capitalismo. Nos
1 A noção de desfiliação, para Castel, "pertence ao mesmo campo semântico que a dissociação, a desqualificação ou a invalidez social" (1998, p. 26). Refere-se à situação do sujeito que não mais encontra proteção e tutela nos processos de sociabilidade primária e secundária (com intermediação de ins titu $i$ ço es específicas), ou seja, que se encontra sem respaldo social. O autor utilizou esse conceito para analisar os mecanismos de suporte social relacionados ao assalariamento, destacando o papel das instituições públicas que configuram o Estado de Bem-Estar. Nesta pesquisa, a conceituação de filiação social é utilizada de maneira mais ampla. Entende-se por filiação social os processos que legitimam/reconhecem os sujeitos sociais, sendo que tais processos não necessariamente se dão pelo assalariamento, apesar de este ainda persistir como um facilitador de maior/ melhor inscriçãol inserção social. 
estabelecimentos de ensino, através de mecanismos disciplinares e hierárquicos, ocorre uma distribuição serial de lugares sociais, visando a um maior controle das atividades e a uma preparação subjetiva dos futuros trabalhadores. O controle do tempo, do espaço, das atividades nas escolas prepara as crianças e os jovens para a inserção no mercado fabril através da interiorização da disciplina.

O discurso da instituição escola se fortaleceu socialmente pela atrelagem entre educação e preparação para o trabalho. A família enviava seus filhos para que estes fossem educados para uma inserção social e profissional. Por longo tempo, as escolas cumpriram suas funções de disciplinarização e docilização, características necessárias no regime tayloristafordista que imperava nas fábricas. No entanto, com as modificações nos modos de gestão, com a implantação e a difusão da informatização e dos novos processos tecnológicos, as empresas passaram a fazer outras exigências de contratação. Flexibilidade, capacidade de resolução de problemas, criatividade, autonomia, tornaram-se requisitos das empresas à contratação, além da experiência profissional e da qualificação escolar formal, o que conduz a crises de função e de ação nos ambientes escolares, pois o modelo construído para o capitalismo tayloristafordista não mais atinge seus objetivos primeiros de preparação para o trabalho.

Nos últimos anos, configurou-se um modo de trabalho mais flexível. No entanto, apesar do ataque à burocracia e uma certa noção de que o novo modelo permite maior liberdade às pessoas, tem-se claro que essa flexibilização impõe novas relações de poder e de controle, ao invés de simplesmente abolir as regras do passado (Sennett,1999). Essas mudanças atingem o modo de viver e de se constituir. Um movimento diferente das forças de subjetivação emerge com o advento da flexibilização, do subemprego e do desemprego, substituindo, parcialmente, o processo de vida linear que era sustentado pela premissa da garantia de inserção social.
Diante desse quadro, a dúvida sobre como construir os caminhos futuros e sobre os riscos que valem uma aposta promove ansiedade. A produção de si encontra-se diante de um impasse: uma produção de subjetividade que não responde às exigências contemporâneas e à necessidade de inserção social e de fazer parte do mundo. A questão da adolescência é um bom exemplo de tal complexidade e paradoxo, pois, nos jovens, há a exigência de inserção e de mudança de estatuto social - assunção da adultez - pelo trabalho, num mercado que, ao fechar suas portas, Ihes nega esse lugar.

É possível que, na impossibilidade de cumprir a norma social pró-trabalho assalariado, a ansiedade e o sentimento de fracasso atinjam níveis por demais estressantes. No intuito de dar conta dessa situação, o jovem busca outros pontos de apoio. Alguns dados, como o aumento dos níveis de gravidez na adolescência, o aumento dos índices de violência, de vandalismo e de uso de drogas talvez denotem tentativas de inserção num modelo social liberal que convoca a um trabalho não mais tão disponível. Existem estudos que apóiam essa hipótese, como o de Pochmann (2000), que destaca que o contexto de desemprego fragiliza a percepção do jovem de que, através do trabalho, possa superar suas dificuldades.

Com baixas perspectivas de futuro, o jovem passa a conectar-se a outros valores, como a violência, a drogadição, o individualismo. Aqui podemos tomar a discussão feita por Robert Castel em uma entrevista proposta por François Ewald (1997) acerca do "individualismo negativo". Este ocorre quando as pessoas se desligam da proteção geral ou da participação em coletivos, tornando-se, cada vez mais, indivíduos sem suporte, portanto, desprovidos de proteção social.

Como enfatiza Sennett (1999), temos uma geração à deriva. A incerteza, a dificuldade de planejamento a longo prazo tornaram-se corriqueiras. "O que é singular na incerteza de hoje é que ela existe sem qualquer desastre 
histórico iminente; ao contrário, está entremeada nas práticas cotidianas de um vigoroso capitalismo. A instabilidade pretende ser normal..." (Sennett, 1999, p.33). Isso se visualiza, no campo do trabalho, nos dados destacados por Pochmann (2000b), quando este enfatiza que o jovem atualmente consegue trabalho em "bicos" ou estágios rápidos, nada que aponte a um futuro profissional ou a uma estabilidade. Tal cenário acaba confirmando a condição de vulnerabilidade social em que se encontra com relação à inserção e à continuidade profissional.

Se, em décadas passadas, o trabalhador conseguia vislumbrar o trabalho como um norteador da vida ou como algo que possibilitasse uma certa construção atrelada à mobilidade social, hoje o jovem, pelas características de flexibilização e precariedade do trabalho assalariado, por vezes se vê à deriva, sem referenciais claros, sem rumos a priori. Não há mais padrões de estabilidade. A instabilidade passa a ser algo bastante presente e a engendrar modos de ser diferentes dos tempos anteriores.

É possível que essa instabilidade enfraqueça o dispositivo de mobilidade social. Dados da Organização das Nações Unidas - ONU informam que a juventude brasileira se encontra em segundo lugar no ranking de pessimismo no que tange a trabalho. Sete em cada dez brasileiros não acredita que terá um futuro com condições de viver e trabalhar melhor que seus pais (Pochmann, 2000).

Para tornar esse cenário mais complexo, conforme Pochmann, na década de 90, a taxa de desemprego juvenil apresentou uma tendência de elevação sistemática. A título de comparação, nos anos oitenta, a taxa de desemprego juvenil era 4,6\%, três vezes menor que a taxa de 16\% de 1998 (Pochmann, 2000) Em outro trabalho, complementa que 48\% (nível nacional) dos desempregados estão na faixa etária dos 15 aos 24 anos (Pochmann, 2000b).
Essas informações apontam um grande contingente de jovens à procura de seu primeiro emprego, este último compreendido como a relação de trabalho assalariado formal (com carteira assinada), e que, portanto, se encontram alheios à proteção social e aos processos de inserção/inscrição sociais.

Para corroborar a importância de discutirmos os efeitos desse cenário social, esse mesmo autor informa que, apesar de existir uma queda na taxa de expansão da população entre 15 e 24 anos, está previsto que teremos o ponto máximo em termos de quantidade absoluta de sujeitos nessa faixa etária ainda na primeira metade da década de 2000 (Pochmann, 2000b).

Devido a essa situação, urge que se conheçam as estratégias que esses jovens estão encontrando/utilizando para tornarem-se sujeitos de suas próprias ações, pois como afirma Deleuze:

"...esquecemos rapidamente os velhos poderes que não se exercem mais, os velhos saberes que não são mais úteis, mas, em matéria de moral, não deixamos de depender de velhas crenças, nas quais nem mesmo cremos mais, e de nos produzirmos como sujeitos em velhos modos que não correspondem mais aos nossos problemas..." (1988, p.114).

Sucintamente temos, então, um arranjo social que entra em crise devido às sérias modificações sociais nas últimas décadas, pois prepara-se o homem, ou melhor, o futuro trabalhador, para algo que não mais existe nas mesmas condições: o pleno emprego.

Esse cenário nos coloca diante de algumas questões que se foram configurando num desejo, aqui tomado como algo que impele à ação de pesquisa. Por trabalhos realizados anteriormente com desempregados e com jovens, crescia a vontade de saber - sentido nietzschiano - como se davam os processos de subjetivação de jovens que, disciplinados "...esquecemos rapidamente os velhos poderes que não se exercem mais, os velhos saberes que não são mais úteis, mas, em matéria de moral, não deixamos de depender de velhas crenças, nas quais nem mesmo cremos mais, e de nos produzirmos como sujeitos em velhos modos que não correspondem mais aos nossos problemas..."

Deleuze 
por inúmeras instituições para um dever ser trabalhador/adulto, encontravam um mundo que lhes negava esse lugar? Será que essa outra configuração social mobiliza forças disruptoras? Promove outros movimentos de subjetivação? Quais os processos de resistência e de subjetivação frente ao cenário de desemprego?

\section{Encontrando jovens em busca do primeiro emprego}

Para responder a essas questões, buscamos encontrar jovens que estavam à procura de seu primeiro emprego. Para tanto, viabilizamos uma parceria de pesquisa com o Programa do Estado do Rio Grande do Sul - Primeiro Emprego, ação governamental de inserção de jovens de 16 a 24 anos, sem relação formal de emprego anterior (Lei n 11.363, de 30 de julho de 1999).

Foram realizadas 20 entrevistas com inscritos no Programa, sendo 15 com jovens que estavam candidatando-se a uma vaga e as restantes com jovens que haviam sido contratados através do mesmo.

A fim de pesquisar os modos de subjetivação dos jovens de 16 a 24 anos, optamos por entrevistas semi-estruturadas, pois estas permitem-nos melhor acessibilidade às percepções, sensações e entendimentos dos sujeitos entrevistados. Buscávamos enunciados que elucidassem a experiência da busca do primeiro emprego.

As entrevistas foram gravadas em áudio-tape e transcritas. A análise destas se efetivou a partir do referencial arquegenealógico foucaultiano, que nos aponta a importância da análise do contexto socio-histórico e do poder enunciativo de certas falas.

Primeiramente, o entendimento de enunciado foi tomado na sua significação latina "enunciatu": "expresso, declarado... resultado da produção discursiva, levando-se em conta o contexto em que ocorreu..." (Ferreira, 1999, p. 774). Mas, a seguir, agregamos a problematização feita por Michel Foucault sobre o termo:

“O enunciado não é uma unidade do mesmo gênero da frase, proposição ou ato de linguagem; não se apóia nos mesmos critérios; mas não é tampouco uma unidade como um objeto material poderia ser, tendo seus limites e sua independência. (...) O enunciado não é, pois, uma estrutura (isto é, um conjunto de relações entre elementos variáveis, autorizando assim um número talvez infinito de modelos concretos), é uma função de existência que pertence exclusivamente aos signos e a partir da qual se pode decidir, em seguida, pela análise ou pela intuição, se eles "fazem sentido" ou não, segundo que regra se sucedem ou se justapõem, de que são signos e que espécie de ato se encontra realizado por sua formulação (oral ou escrita)" (Foucault, 1997, pp. 98-99).

Desse modo, o enunciado pode ser tomado na sua função de "elucidação" da existência de certos discursos. Cabe aqui destacar que entendemos que a linguagem não é um simples meio de transmitir pensamento, comunicar; ela faz bem mais do que isso, pois insere-se como uma prática individual e coletiva, historicizada, marcada pelo tempo e pelo espaço (Briggmann, 1996).

Pela análise dos dados, algumas categorias se configuraram por sua recorrência e poder enunciativo. São elas: relação familiar, qualificação, consumo, independência e "qualquer coisa, alguma coisa". Tais categorias são apresentadas ao longo da discussão dos dados da pesquisa.

\section{Jovens tentando entrar no mundo do trabalho}

Os dados da pesquisa apontam uma produção de subjetividade marcada pela confrontação dos ideais éticos pró-trabalho assalariado e o contexto social de desemprego. Os jovens entrevistados buscam a inserção social por motivos de ordem moral e financeira. Compreendem que atingirão sua adultez quando forem capazes de sustentar-se 
financeiramente e sofrem diante do contexto social de desemprego que dificulta a inserção no mundo do trabalho e a assunção de novos papéis sociais.

O contexto de desemprego é tão presente que, para responder à objetivação social/familiar, o jovem está a ponto de aceitar "qualquer coisa". Com o transcorrer das entrevistas, despertavam a atenção expressões do tipo: "qualquer coisa, alguma coisa", que apontavam uma certa ausência de possibilidade de escolha. Por exemplo, diante do questionamento de que tipo de emprego/trabalho ou remuneração estavam pretendendo, ouvíamos: "Agora, para mim, qualquer coisa. Qualquer coisa que dê para melhorar as coisas. Hoje em dia não dá para ti escolher emprego" (Tábata, 21 anos) ${ }^{2}$. "Como a gente não tem experiência, então não dá para exigir muito. Mas se fosse, eu gostaria de trabalhar em escritório, como secretária..." (Nair, 22 anos). O "mas se fosse" denota a vontade de poder sonhar, quem sabe escolher/planejar um futuro. Algo que parece distanciar-se a cada dia. Quanto mais tempo ficam a procurar por uma colocação laboral, maior é a renúncia a suas vontades, a seus sonhos, a si próprio.

No caso dos jovens pesquisados, a dominação do modo capitalista de pensar tem se mostrado tão efetiva que mina os processos de resistência, levando os jovens a uma espécie de renúncia de si mesmos, em nome do ideal de inserção no sistema. Nesse processo, é claro que o sofrimento se faz presente, pois há o "aplacamento do desejo/da potência".

O sofrimento decorre da impossibilidade/ dificuldade de o sujeito dar sentido a sua força. Como salienta Nietzsche "...antes de tudo o vivente quer dar vazão a sua força - a própria vida é vontade de potência" (1885/1999, p.305). Nesse ponto, é interessante pontuarmos a discussão nietzschiana sobre a moral aristocrática (dos senhores) e a moral gregária (dos escravos). Giacóia (2001) chama a atenção para a relação entre esses dois tipos de moral e a distinção entre ação e reação. A moral aristocrática identifica-se com um tipo predominantemente ativo e afirmativo, enquanto a moral escrava é identificada pela reação a estímulos externos, pela negatividade, não existindo a espontaneidade da ação.

Trazemos essa distinção à nossa discussão, pois nossos dados apontam o prevalecimento da moral escrava e, em conseqüência, de tipos ressentidos. "O tipo ressentido é aquele no qual ocorre uma inibição ou bloqueio na capacidade de descarga de energias e afetos em direção ao exterior" (Giacóia, 2001, p. 83). O tipo escravo tem dificuldade na elaboração ativa dos estímulos externos, o que o leva a processos de ressentimento. Seu modo de descarga de afeto e de alívio da dor é a intensificação de uma outra espécie de sofrimento psíquico: o automartírio da consciência de culpa (Giacóia, 2001).

São os processos de autoculpabilidade que evidenciam as relações com a moral gregária. Os jovens acham que não fizeram cursos suficientes, que não se qualificaram, que não estudaram em locais adequados, que não atingem individualmente as exigências do mercado. Porém, por vezes, percebem, numa posição mais crítica, que, mesmo quando procuram fazer as coisas certas, cumprindo as normas do mercado, ainda assim não são contratados. Ressentem-se com o sistema, um sistema que não os auxilia na inserção, amarramse pela negatividade. Como aponta Giacóia:

".... ressentimento é um processo reativo, que pressupõe a vivência de sofrimento e a necessidade de desembaraçar-se dela por meio de uma descarga súbita de um afeto vigoroso, como meio de narcotização da consciência. $O$ entorpecimento éo elemento positivo e principal; a busca de um culpado e a própria descarga são efeitos secundários, reação à experiência de sofrimento" (2001, p. 84).

Os sujeitos dessa pesquisa ora sentem raiva, ora desânimo - vontade do nada -, ora culpa.

\section{"... o ressentimento é um processo reativo, que pressupõe a vivência de sofrimento e a necessidade de desembaraçar-se dela por meio de uma descarga súbita de um afeto vigoroso, como meio de narcotização da consciência. $\mathrm{O}$ entorpecimento é o elemento positivo e principal; a busca de um culpado e a própria descarga são efeitos secundários, reação à experiência de sofrimento" \\ Giacóia}

2 Os nomes dos entrevistados são fictícios. 
É no interjogo da moral escrava que vão/estão se constituindo. Em um texto de Brusotti, temos a seguinte afirmação: "A crueldade deve, de algum modo, descarregar-se: por falta de algo melhor, para o interior, contra o próprio sujeito. A vontade deve, necessariamente, querer algo, por falta de algo melhor, o nada" (2000, p. 6).

"Nietzsche pensa o sofrimento pela ausência de sentido, de acordo com o modelo de sofrimento da força que não se pode descarregar para fora" (Brusotti, 2000, p. 7). A impossibilidade da ação da vontade de potência leva ao sofrimento.

Para Nietzsche (apud Giacóia, 2001, p. 89), "o homem moderno é fraco, porque é puramente artifício, porque em sua alma não vibram mais as forças vitais autênticas. "O refinamento da consciência moral, marca da modernidade, resultou “...numa intensificação patológica do sentimento de culpa, que hipnotiza o psiquismo e esteriliza o agir" (Giacóia, 2001, p. 89).

Numa teorização foucaultiana, poderíamos inferir que os processos de subjetivação contemporâneos estão marcados por uma preponderância das forças de objetivação/ escravidão, que se efetivam pela restrição das possibilidades de escolha.

A restrição das possibilidades de escolha afeta a liberdade, que, por sua vez, afeta os processos éticos, pois, ao afirmarmos que a ética é a prática reflexiva da liberdade e que esta última é marcada por possibilidades, a constrição do leque de escolhas leva a um empobrecimento dos processos reflexivos (Foucault, 1985). Então, a crítica que se faz quotidianamente aos jovens, dizendo que eles não pensam, não criticam o mundo, responsabiliza-os por algo que de fato é uma construção social.

Em princípio, entendíamos que os jovens que não conseguiam sua inserção social pela via do trabalho remunerado buscavam outros pontos de apoio social (voluntariado, grupos religiosos de jovens, etc) como forma de resistência social. Entretanto, os dados da pesquisa denotam um empobrecimento das relações, um afastamento dos processos coletivos. Esses resultados vêm ao encontro da discussão feita por Castel (1997) sobre o individualismo negativo.

Os jovens parecem restritos ao ambiente familiar. "Eu saio de vez em quando. Eu gosto muito de ver TV (...) Eu moro com a minha avó; então ela é muito: ah, vamos ficar com a família. Tem uma tia que mora junto de nós. Tem janta em família, almoço em família, aniversário em família" (Nair, 22 anos). "Levanto. Tomo café. Arrumo a casa. Quando tem que levar o meu irmão no colégio, eu levo. Depois eu busco. E depois eu fico em casa, nada..." (Joana, 18 anos). "Fico em casa vendo TV. Às vezes, saio, jogo uma bola, alguma coisa assim" (José, 18 anos).

Nardi (1999), discutindo as relações entre adoecimento e trabalho, afirmou que a vivência do adoecimento profissional é marcada pela individuação da doença e que um dos elementos que constitui tal processo é o isolamento. Este, por sua vez, caracteriza-se pelo retorno ao espaço doméstico e pela perda do referencial do trabalho como elemento de inscrição social, levando ao enfraquecimento dos relacionamentos fora do âmbito familiar. Guardadas as particularidades das populações pesquisadas e as diferentes vivências em relação ao mundo do trabalho, nossos dados também apontam o isolamento social.

Retornando à afirmação de Ariès (1981) de que a família moderna parece substituir as antigas relações sociais a fim de permitir ao homem escapar de sua solidão moral, esses jovens parecem confirmar que o espaço familiar é o ambiente de socialização que faz frente, ou seja, que opera como resistência à desfiliação 
social de seus membros. Os jovens, se ainda não são trabalhadores, precisam encontrar na família algum espaço de reconhecimento social, mesmo que este se dê na categoria de filhos.

Apesar da existência de uma rede discursiva na fala dos familiares que convoca ao assalariamento, formulados em enunciados do tipo: "tu tem que ter teu dinheiro" ou "quem não trabalha é vagabundo", cabe à família continuar provendo a sustentação subjetiva e material de seus jovens que ainda não trabalham.

Isso se torna mais complexo com a saída da escola, pois esta representa um espaço de socialização. $\mathrm{O}$ ambiente escolar oferece a possibilidade de reconhecimento de um sujeito social - o aluno. Sarriera et alli (2000, p. 45), referindo-se ao jovem que termina o ensino médio, afirma:

"A saída da escola supõe para o jovem um período de transição. Sai de uma instituição organizada e organizadora para um espaço social no qual o tempo e a atividade não estão tão estruturados. O papel, antes do aluno, torna-se um papel confuso e pouco definido. Esse novo espaço de transição é chamado de terra de ninguém, isto é, nenhuma instituição social se responsabiliza pelo jovem nessa fase. Nesse momento, o jovem passa a ser pressionado pela família para mostrar a sua capacidade de conseguir um trabalho que complemente a renda familiar" (2000, p. 45).

Os dados desta pesquisa concordam em parte com essa afirmação. Como já afirmei acima, as entrevistas demonstram que a família incentiva a inserção no mercado de trabalho, mas que também é ela que está fazendo frente a esse não-lugar. Explico: são os laços familiares que sustentam/filtram a sensação de não-inserção.

Ficou bastante evidente nas entrevistas que os jovens com "melhor" relacionamento familiar sentiam-se acolhidos e menos pressionados a aceitarem "qualquer coisa". Como evidencia a fala de uma jovem que afirmou que, por ter família, ainda não precisava submeter-se a entregar panfletos na rua (Manoela, 16 anos). A acolhida se materializava em frases familiares do tipo: "Ah, a próxima vez tu consegue. De repente, não era... Eles diziam muito que não era para ser meu, que quando chegasse a hora, eu ia conseguir" (Paula, 18 anos, empregada).

Entre a convocação discursiva feita pela família para que o jovem assuma o lugar social de trabalhador e a realidade de desemprego deste, encontramos um tensionamento paradoxal que configura e altera a própria convocação próassalariamento. A mesma família que objetiva o assalariamento precisa dar suporte ao jovem quando este não consegue corresponder a essa norma subjetivante.

Em algumas entrevistas, observa-se um certo misticismo, uma religiosidade que aplaca a angústia das buscas sem resultados pela explicação de que existe uma hora certa, um destino. Talvez estas possam ser compreendidas como um resquício católico de que o céu está garantido pelo sofrimento. Uma jovem já empregada relembra a sensação de quando saía a procurar emprego: "A sensação que eu tinha era que...seja o que Deus quiser...porque tinha gente que tinha muito mais curso que eu, né?" (Diana, 19 anos, empregada). "Às vezes, eu fico com medo. Às vezes, eu fico pensando: ah, vai ter bastante gente qualificada, né? Vai ter bastante gente com faculdade. Vai ter bastante gente que não é qualificada. Mas, eu acredito em Deus. Eu rezo todos os dias. Eu acho que uma hora vai aparecer um serviço pra mim. Não sei. Eu acho que uma hora vai acontecer. Se não foi ontem, vai ser amanhã ou depois, não sei" (Joana, 18 anos). Parece, aos jovens que buscam o primeiro emprego, que existe um Deus que escreve certo por linhas tortas, sendo que esse misticismo se apresenta como defesa contra o sofrimento, uma crença necessária que consola.

Quanto à utilização da remuneração, apesar de a maioria dos jovens ser proveniente de
"A saída da escola supõe para o jovem um período de transição. Sai de uma instituição organizadae organizadora para um espaço social no qual o tempo e a atividade não estão tão estruturados. 0 papel, antes do aluno, torna-se um papel confuso e pouco definido. Esse novo espaço de transição é chamado de terra de ninguém, isto é, nenhuma instituição social se responsabiliza pelo jovem nessa fase. Nesse momento, o jovem passa a ser pressionado pela família para mostrar a sua capacidade de conseguir um trabalho que complemente a renda familiar"

Sarriera et alli 
famílias com pouco recurso financeiro, a perspectiva de receber algum dinheiro não estava particularmente atrelada a um auxílio das despesas domésticas. Isso não significa dizer que os jovens não auxiliariam no orçamento familiar, mas que as falas destacavam que o objetivo do salário não era subsistência imediata. Esta parecia estar a cargo das famílias, enquanto, ao jovem, cabia encontrar maneiras de sustentar seu consumo individual. "Ai. É porque assim oh: os meus pais trabalham, né? Só que tem necessidade. Às vezes, eu quero sair, dar uma volta, aí tem que pedir pra minha mãe. Qualquer coisa assim. Não é a mesma coisa que tu trabalhar, ter teu dinheiro e poder sair. Claro que eu posso comunicar ela, mas daí eu não preciso ficar pedindo dinheiro. Às vezes, eu quero vir ao centro, comprar uma calça, daí tem que ficar pedindo dinheiro pra ela, então é mais ou menos pra isso. E pretendo fazer um cursinho e ingressar na faculdade" (Joana, 18 anos). "Porque eu gostaria de ter meu próprio, pra quando eu quiser sair, não depender do meu pai, pra ter as minhas coisas. Em geral, pra mim comprar as coisas que eu quero" (Renato, 16 anos).

Com os dados até aqui apresentados, podemos pontuar a relação entre "capacidade de consumo" e uma certa sensação de "independência", que se mostra fundamental nos discursos no que tange à motivação pela busca laboral. Vetor importante na movimentação por um "emprego/trabalho" é um certo desejo de "independização", que, por vezes, vem atrelado à questão do "consumo". "Olha a minha vontade é ser independente. A minha vontade é não depender desse dinheiro" (pensão que recebe do pai falecido) (Salete, 20 anos). "Porque eu não posso ficar a vida inteira dependendo de alguém, né? Eu tenho que saber... (...) então um emprego pra mim é aprender (...) Pra pensar no futuro. Eu pretendo fazer uma faculdade. Eu quero fazer fisioterapia. Até para ajudar a pagar, né? É muito caro. Mais é pra isso, né? Pra ter o meu dinheiro. A minha independência" (Nair, 22 anos).
Pela via do "consumo", capta-se um ideário social que paira: quem tem dinheiro consome. Para ter dinheiro, é necessário trabalhar... Quem trabalha pode decidir o que, quando e como comprar. Uma jovem chega a dizer, ao comentar sobre os amigos que trabalham: "Quando eu saio com eles, eles colocam: ah, que eu tô trabalhando, que eu tô ganhando, claro que ninguém comenta salário, mas que eu tô trabalhando numa coisa que eu gosto, tenho a minha independência, quero morar sozinha. Daí pode planejar um futuro, sabe? Quem tá trabalhando, acho que tem pelo menos o direito de tu... de tu achar o teu futuro. Porque tu não tá dependendo de alguém" (Nair, 22 anos).

O trabalho, para esses jovens, é a porta de entrada em um novo mundo: um mundo de consumo. Parece-lhes, no contexto atual, que mais importante do que ser um trabalhador é ser um consumidor. Isso se efetiva pela dificuldade de inserção profissional, que prejudica a realização dos planos de vida e um certo planejamento de futuro. $O$ ato de trabalhar acaba restringindo-se a um possibilitador de consumo. Para esses jovens, o sonho de se realizarem como sujeitos se vê enfraquecido. Fazem o que lhes mandam. Aqui retomamos o entendimento da escravidão. Não há proposições novas. Buscam ser aquilo que pensam que os outros querem que sejam. Para ser contratado, precisa saber inglês, então tenho que estudar inglês. Tem que saber informática, então preciso matricular-me num curso de informática. Tem que estar bem vestido e saber falar bem, então me comportarei. A escravidão os empurra à fraqueza, à renúncia, ao aplacamento de si.

\section{Para finalizar...}

Abordar a temática do desemprego juvenil constitui desafio que permanece pela sua atualidade. A dificuldade de inserção laboral dos jovens em busca de seu primeiro emprego ganhou destaque em jornais e telejornais nos últimos anos. Trata-se de um problema social que repercute nos modos de ser de uma geração.

Os dados desta pesquisa evidenciaram uma parcela da população jovem que encontra sérias 
dificuldades de inserção profissional e que não tem mais o trabalho como algo que norteia positivamente a vida. Encontram-se à deriva profissional. Agarram-se a quaisquer possibilidades de inserção. No contexto de quebra da linearidade profissional e de mobilidade social, amarram-se à negatividade do não ter. Ressentem-se com a não-inserção e encontram dificuldades de constituírem outros modos de engendrar a existência.
Nesse cenário, os programas de inserção profissional se fazem necessários. Entretanto, entende-se que o campo de ação destes não pode restringir-se exclusivamente ao financiamento de uma parte da remuneração do jovem. É preciso que, no rol de suas ações, estejam incluídas atividades de reflexão e de aprendizagem de outros modos de trabalhar como, por exemplo, o trabalho cooperativado e de economia solidária.
Luciana Fim Wickert

Psicóloga. Psicanalista. Mestre em Psicologia Social e Institucional/UFRGS. Av. Protásio Alves, 7149, ap. 201. Alto Petrópolis Porto Alegre/RS CEP: 91310-003 Fones: (51) $33517262-8111.8885$ E-mail: luwickert@uol.com.br

Recebido 22/06/04 Reformulado 26/05/06 Aprovado 29/05/06

ARIÈS, P. História Social da Criança e da Família. Rio de Janeiro : LTC, 1981.

BRIGGMANN, A. P. Discurso: Estrutura, Evento ou Processo? Educação, Subjetividade e Poder, 3, no 3. Porto Alegre: Núcleo de Estudos sobre Subjetividade, Poder e Educação. Programa de PósGraduação em Educação - UFRGS; ljuí: Unijuí, pp. 31-36.

BRUSOTTI, Marco. Ressentimento e Vontade de Nada. Cadernos Nietzsche, no 8. São Paulo: 2000, pp. 3-34.

CASTEL, R. As Metamorfoses da Questão Social: uma Crônica do Salário. Petrópolis : Vozes, 1998.

CATTANI, A. D. As Transformações no Mundo do Trabalho e os seus Conceitos. In Trabalho e Tecnologia: Dicionário Crítico. Org. Antonio David Cattani. Petrópolis : Vozes, 1999, 2ª ed.

COLBARI, A. L. Ética do Trabalho:a Vida Familiar na Construção da Identidade Profissional. São Paulo : Letras e Letras, da FCAA/UFES, 1985.

DELEUZE, G. Foucault. São Paulo : Brasiliense, 1988.

EIZIRIK, M. F. Ética e Cuidado de Si: Movimentos da Subjetividade. Educação, Subjetividade e Poder, no 4. Porto Alegre : Núcleo de Estudos sobre Subjetividade, Poder e Educacão, Programa de PósGraduação em Educação - UFRGS, Editora Unijuí, 1997.

EWALD, F. Robert Castel: o Advento de um Individualismo Negativo - Entrevista Proposta por François Ewald. Revista do Departamento de Psicologia-UFF, 9, $\mathbf{n}^{\circ} \mathbf{2}$ e 3, 1997, pp. 4-12.

FERREIRA, A. B. de H. Novo Aurélio Século XXI: o Dicionário de Língua Portuguesa. Rio de Janeiro: Nova Fronteira, 1999, p. 774.

FOUCAULT, M. História da Sexualidade 3: o Cuidado de Si. Rio de Janeiro: Graal, 1985.

Vigiar e Punir: Nascimento da Prisão. Trad. de Raquel Ramalhete. Petrópolis : Vozes, 1987.
El Sujeto y el Poder. Revista Mexicana de

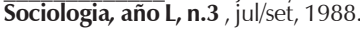

AArqueologia do Saber. Trad. de Luiz Felipe Baeta Neves. Rio de Janeiro : Forense Universitária, 1997.

GIACÒIA JUNIOR, O. Nietzsche como Psicólogo. São Leopoldo : Unisinos, 2001

NARDI, H. C. Saúde, Trabalho e Discurso Médico: Relacão Médico-Paciente e o Conflito Capital-Trabalho. São Leopoldo : Unisinos, 1999.

Trabalho e Ética: os Processos de Subjetivação de duas Geraçóes de Trabalhadores Metalúrgicos e do Setor Informal (1970-1999). Tese de Doutorado em Sociologia. Universidade Federal do Rio Grande do Sul, 2002.

NIETZSCHE, F. Para além do Bem e do Mal: Prelúdio de uma Filosofia Porvir. In Os Pensadores - Nietzsche: Obras Incompletas. São Paulo : Nova Cultural, (1885)1999.

ORTEGA, F. Amizade e Estética da Existência em Foucault. Rio de Janeiro : Graal, 1999.

POCHMANN, M. A Batalha pelo Primeiro Emprego. São Paulo : Publisher Brasil, 2000.

Existe Saída para os Jovens. In Zero Hora Caderno de Empregos. Porto Alegre, 16 de julho de 2000.

RIO GRANDE DO SUL. Lei $\mathbf{n}^{\circ} \mathbf{1 1 . 3 6 3}$, de 30 de julho de 1999. Institui o programa Primeiro Emprego - PPE e dá outras providências. Porto Alegre, 1999

SARRIERA, J. C. et alli. Os (Des) Caminhos dos Jovens na sua Passagem da Escola ao Trabalho. In Psicologia Comunitária: Estudos Atuais. Jorge Castellá Sarriera (org). Porto Alegre : Sulina, 2000, pp.45-63.

SENNETT, R. A Corrosão do Caráter: Conseqüências Pessoais do Trabalho no Novo Capitalismo. Rio de Janeiro : Record, 1999.
Referências 